\title{
Modeling the Effects of Financial Constraints on Firm's Investment
}

\author{
Gian Maria Tomat \\ Bank of Italy, Rome
}

\begin{abstract}
:
The paper develops a model of firm's investment under uncertainty with financial market imperfections and analyzes the effects of financial constraints on firm's investment. Firm's investment is an increasing function of the firm's marginal $q$, however the investment function is characterized by an upper bound that depends on the firm's borrowing capabilities. The firm's marginal $q$ is the sum of the expected value of the marginal profitability of the physical capital stock and of a positive external finance premium. In the presence of financial market imperfections the firm forms expectations about future financial conditions and these expectations raise the firm's current marginal $q$. Similarly, the shadow price of firm's debt is the sum of the interest cost of debt repayment and of a provision for external finance that depends on the firm's expectations over future financial conditions.
\end{abstract}

JEL: D92, E22

Keywords: Firm's investment; financial constraints; Tobin's marginal q, uncertainty

Correspondence:

Bank of Italy, Economic Research, Via XX Settembre 97/E, 00187 Rome, Italy, Tel.: +39-06-47923179, Fax: +39-06-47925405, Email: giannmaria.tomat@bancaditalia.it

Paper presented at IX Workshop on Quantitative Finance, University of Rome "Tor Vergata", January 24-25, 2008. I thank Luigi Cannari, Riccardo De Bonis, Roberto Golinelli, Massimo Omiccioli, Giuseppe Parigi, Carmelo Salleo, Sergio Scarlatti, Roberto Violi and Giordano Zevi for helpful comments and suggestions on earlier drafts of this work. The views contained in the paper are the author's and do not necessarily reflect those of the Bank of Italy. 


\section{Introduction}

The purpose of this paper is to study the effects of credit constraints on firm's investment, we follow the approach to the analysis of the investment function that is reviewed in Abel and Eberly (1994). This approach has so far been used mainly to study the effects on firm's investment that are determined by the existence of capital adjustment constraints. We extend the framework in order to account for financial market imperfections and for the presence of credit constraints.

The effects on firm's investment of capital market imperfections have been recently analyzed by a new field of literature, which is reviewed in Bertola and Caballero (1990) and Caballero (1990, 1993, 1994). These works emphasize the importance of non-convexities in the adjustment cost function for firm's investment patterns. In particular, they show how the assumption of non-convexities in the adjustment cost function allows to model the effects of irreversibility and lumpy investment that are usually found in empirical studies of investment at the firm's level. Within this approach the effects of credit constraints on firm's investment must, however, also be modeled by making of assumptions on the shape of the adjustment cost function. This feature introduces in the framework a problem of identification, since in this way the effects on firm's investment of changes in credit constraints cannot be distinguished from those of other changes of the adjustment cost function.

The approach adopted in the paper, rather than concentrating on the adjustment cost function, follows previous research and characterizes explicitly the firm's borrowing choices and the firm's borrowing constraints. The model in the paper presents some of the features common to most of the recent empirical work on the relation between finance and investment.

The main results of the paper concern the relation between investment and the firm's marginal $q$. The paper shows that, as in the case of perfect financial markets, there is a positive relation between firm's investment and marginal $q$, although in the presence of financial constraints there is an upper bound to firm's investment and in each time period investment is constant if the firm's marginal $q$ is greater than or equal to a given threshold value. A second result concerns the effects of credit constraints on the firm's marginal $q$. The paper shows that the firm's marginal $q$ is the sum of a component representing the expected present discounted value of firm's profitability and of an external finance premium that is defined by the firm's expectations about future credit conditions. These findings conform to a similar pattern that is usually found in studies of the consumption function and have an important implication for applied econometric research, because they suggest that measures of expected future credit conditions should be an important component of estimated investment equations.

The paper shows, therefore, that in the presence of financial constraints the Modigliani and Miller $(1958,1963)$ results on the effects of the firm's financial policy are not satisfied along an optimal investment path. In the final parts of the paper some additional results concerning the relation between financial constraints and the shadow price of firm's debt are presented. In particular, it is claimed that while in the case of perfect financial markets the firm's investment choices are independent from the firm's financial structure and the shadow price of firm's debt is defined by the interest payments that must be afforded by the firm for each additional marginal unit 
of debt, in the presence of financial market imperfections instead the firm's financial structure is important. The paper shows that with imperfect financial markets the shadow price of firm's debt is the sum of the interest payments on each additional marginal unit of debt and of a provision for external finance, that is defined in terms of the firm's expectations about future credit conditions.

The structure of the paper is the following. Section 2, defines the model. Section 3 , characterizes the firm's optimization problem. Section 4, studies the firm's investment function. Section 5, characterizes the shadow price of capital and its behavior in the presence of financial constraints. Section 6 , describes the effects of financial structure on the shadow price of firm's debt. Section 7 , draws some conclusions.

\section{The Model}

Following previous research by Abel (1983, 1985), Abel and Eberly (1994) and Bertola and Caballero (1994), the main elements of the model are characterized with reference to the firm's cash-flow and to the variables that determine its time variation. In the case of perfect financial markets analyzed in these works, the main components of the firm's cash-flow at any given instant of time $t$, are the short-run profit function and the adjustment cost function. In the present work we study the case of imperfect financial markets and therefore the firm's cash flow includes also a term describing the net balance resulting from the firm's financial choices. The modeling choice adopted in the paper involves the use of a continuous time framework.

The short-run profit function defines the firm's operating profit at time $t$, it is usually assumed that it is a function of two state variables, the firm's physical capital stock at time $t$ and a stochastic variable representing the firm's productivity and external market conditions such as the output price. We let the profit function be denoted as $\pi\left(K_{t}, \varepsilon_{t}\right)$, where $K_{t}$ represents the firm's physical capital stock and $\varepsilon_{t}$ the stochastic variation on the firm's profitability at time $t$, and assume that it is increasing, concave and continuously differentiable, such that: $\pi_{K}\left(K_{t}, \varepsilon_{t}\right) \geq 0$, $\pi_{\varepsilon}\left(K_{t}, \varepsilon_{t}\right) \geq 0, \pi_{K K}\left(K_{t}, \varepsilon_{t}\right) \leq 0$ and $\pi_{\varepsilon \varepsilon}\left(K_{t}, \varepsilon_{t}\right) \leq 0$.

The motion of the physical capital stock is determined according to the following continuous time stock-adjustment equation:

$$
\frac{d K_{t}}{d t}=I_{t}-\delta K_{t}
$$

where $\delta$ is the exogenous rate of physical capital depreciation and $I_{t}$ is firm's investment at time $t$.

We assume in addition that the motion of the stochastic state variable $\varepsilon_{t}$ is described by a diffusion process. Letting $d \varepsilon_{t}$ denote the increment of the process in an interval of time of length $d t \rightarrow 0$ :

$$
d \varepsilon_{t}=\mu\left(\varepsilon_{t}, t\right) d t+\sigma\left(\varepsilon_{t}, t\right) d z_{t}
$$

where the functions $\mu\left(\varepsilon_{t}, t\right)$ and $\sigma\left(\varepsilon_{t}, t\right)$ define the drift and the variance of the process at time $t$ and are assumed to be continuous and $z_{t}$ takes the form of a 
standard Brownian motion or Wiener process. ${ }^{1}$

The characterization of the short-run profit function is important for empirical studies of particular industries, or when the research interest regards the effects of particular variables or sources of uncertainty on the firm's patterns of investment. Also note that while we define the stochastic state as a single random variable, the firm might be subject to more than one source of uncertainty and to take this into account the stochastic state variable could be modeled as a vector. We make the assumption of a single stochastic state variable since it simplifies the analysis and given the purpose of the work the extension to a stochastic state vector would not give any additional insights. ${ }^{2}$

The adjustment cost function is usually composed of various components, which include purchase, sale and other variable costs of adjustment and fixed costs of adjustment. For the purposes of the present analysis we suppose that the adjustment cost function is defined as the sum of a convex variable adjustment cost component and of a fixed cost component. Let $a\left(I_{t}, K_{t}\right)$ represent the variable costs of adjustment and $a_{0}$ the fixed cost of adjustment. We assume that the function $a\left(I_{t}, K_{t}\right)$ is convex and continuously differentiable, with a minimum at $I_{t}=0$, such that $a_{I}\left(I_{t}, K_{t}\right) \leq 0$ for $I_{t} \leq 0, a_{I}\left(I_{t}, K_{t}\right) \geq 0$ for $I_{t} \geq 0$ and $a_{I I}\left(I_{t}, K_{t}\right) \geq 0$, for all $I_{t}$ and $K_{t}$. We also assume $a\left(0, K_{t}\right)=0$ for all $K_{t}$ and $a_{K}\left(I_{t}, K_{t}\right) \leq 0$ for all $I_{t}$ and $K_{t}$, the firm does not incur in any variable adjustment cost when $I_{t}=0$ and we suppose that the costs of adjustment decrease as the capital stock increases, since additions to capital stock become then relatively less important. The fixed cost of adjustment must be incurred only when $I_{t}>0$ or $I_{t}<0$, however, we will shortly rule out the latter case.

Denoting with $c\left(I_{t}, K_{t}\right)$ the total adjustment cost function, the above assumptions imply that $c\left(I_{t}, K_{t}\right)$ is equal to zero when the firm is not investing, so that $c\left(0, K_{t}\right)=0$ for all $K_{t}$, and is equal to the sum of the variable and fixed costs of adjustment otherwise, therefore $c\left(I_{t}, K_{t}\right)=a_{0}+a\left(I_{t}, K_{t}\right)$ for $I_{t}>0$ and for all $K_{t}$. Note that due to the presence of a fixed cost component $\lim _{I_{t} \rightarrow 0} c\left(I_{t}, K_{t}\right)=a_{0}$ and this implies that marginal investment projects will not be undertaken. The fixed cost of adjustment defines a threshold for the increase in profitability below which the firm will not find it optimal to adjust its capital stock. Moreover, since convexity of the variable cost component implies $c\left(I_{t}, K_{t}\right)>a_{0}$ for $I_{t}<0$ and the marginal product of capital is positive for all $K_{t}$ and $\varepsilon_{t}$, in each time period the firm will not find it optimal to undertake negative investment.

The assumptions on the adjustment cost function imply that firm's investment is characterized by discontinuities and lumpiness, with periods of investment inactivity followed by periods with relatively high levels of investment. Since negative investment is ruled out, firm's investment is also characterized by irreversibility. These properties conform to the investment patterns that are usually found in empirical

\footnotetext{
${ }^{1}$ An introduction to the notion and properties of diffusion processes can be found in Merton (1990), for a more rigorous treatment see Billingsley (1968).

${ }^{2}$ Various studies have analyzed the implications of different market structures and different sources of uncertainty on firm's investment behaviour. A survey of models and empirical works can be found in Dixit and Pindyck (1994). Extensions to more than one stochastic state variable have also been concerned with the distinction between aggregate and idiosyncratic uncertainty and its implications for modeling aggregate investment. Research in this field can be found for example in the works of Bertola and Caballero (1990, 1994), Caballero and Engel (1999) and Caballero, Engel and Haltiwanger (1995).
} 
studies, which show that at the firm's level investment mostly occurs through discrete jumps, that periods of investment inactivity are relatively frequent and that negative capital adjustment patterns follow mainly the patterns of physical capital depreciation. ${ }^{3}$

Finally, we suppose that in each time period the firm can issue debt at a constant borrowing interest rate $r$ and we let $B_{t}$ denote the firm's debt stock at time $t$ and $N_{t}$ the firm's new debt issue at time $t$. With these assumptions the firm's cash-flow at time $t$ can be defined as:

$$
\varphi\left(I_{t}, N_{t}\right)=\pi\left(K_{t}, \varepsilon_{t}\right)-c\left(I_{t}, K_{t}\right)-r B_{t}+N_{t}
$$

where, for ease of exposition, the dependence of the firm's cash flow on the values of the physical capital stock $K_{t}$, the firm's debt stock $B_{t}$ and the stochastic state variable $\varepsilon_{t}$ is assumed implicitly.

Since interest on the stock of debt is paid by the firm in each time period, the time pattern of the firm's debt stock is determined by new debt issue according to the following differential equation:

$$
\frac{d B_{t}}{d t}=N_{t}
$$

Following the approach that is illustrated in Deaton (1991) for the consumption function, in order to model borrowing constraints in an imperfect financial market, we assume that there is an upper bound $\bar{N}$ to the amount of debt that the firm can issue in each time period:

$$
N_{t} \leq \bar{N}
$$

Moreover, we assume that cash-flow is paid out as dividends to shareholders and restrict cash-flow to be non-negative in each time period:

$$
\pi\left(K_{t}, \varepsilon_{t}\right)-c\left(I_{t}, K_{t}\right)-r B_{t}+N_{t} \geq 0
$$

we can interpret this condition as a restriction on the issue of new shares.

In order to justify this form of the firm's financial constraints we note that equation (2.5) implies that in each period of time $t$ for a given level of initial debt $B_{t}$, the present discounted value of future debt $B_{\tau}$ for $\tau \geq t$ is bounded above. In particular, integrating equation (2.4) over a time interval $[t, \tau]$ leads to $B_{\tau} e^{-r(\tau-t)} \leq$ $B_{t} e^{-r(\tau-t)}+\bar{N}(\tau-t) e^{-r(\tau-t)}$. Note also that $\lim _{\tau \rightarrow+\infty} B_{t} e^{-r(\tau-t)}+\bar{N}(\tau-t) e^{-r(\tau-t)}=0$ and this in turn implies that $\lim _{\tau \rightarrow+\infty} B_{\tau} e^{-r(\tau-t)} \leq 0$. The upper bound on new debt issue therefore rules out investment financed through unlimited borrowing.

The approach of modeling credit constraints imposing an upper bound on the amount of outstanding debt stock has been largely followed in the empirical literature on the consumption function, among others in the works of Hayashi (1985), Zeldes (1989) and Runkle (1991). In the literature on firm's investment the approach of modeling financial constraints in terms of restrictions on the firm's cash-flow and firm's debt has been previously used in the empirical works of Whited (1992) and

\footnotetext{
${ }^{3}$ Empirical evidence on firm's level investment of this type can be found in Doms and Dunne (1998), Cooper, Haltiwanger and Power (1999), Nilsen and Schiantarelli (2003) and Carlson and Laséen (2005).
} 
Hubbard, Kashyap and Whited (1995). Note that while as stated condition (2.5) is only a sufficient condition, it must hold almost everywhere in the real line in order to ensure an upper bound on the firm's debt stock. ${ }^{4}$

The objective of the firm is to maximize the value to shareholders and therefore the firm's optimization problem is to maximize the expected present discounted value of firm's cash flow:

$$
V\left(K_{t}, B_{t}, \varepsilon_{t}\right)=\max _{\{I \tau, N \tau\}_{\tau=t}^{+\infty}} E_{t} \int_{t}^{+\infty} \varphi\left(I_{\tau}, N_{\tau}\right) e^{-\rho(\tau-t)} d \tau
$$

where $\rho$ is the exogenous discount factor, subject to the physical capital accumulation equation (2.1), the law of motion of the stochastic state variable (2.2), the firm's outstanding debt accumulation equation (2.4) and the financial constraints defined by equations (2.5) and (2.6).

In the case of imperfect financial markets we are considering we require $r \leq \rho$ so that the factor that is used to discount cash value to share-holders is characterized by a premium over the rate at which the firm can borrow in the financial market. Given the above model, the case of perfect financial markets obtains as the limit for $\bar{N} \rightarrow+\infty$, by removing the cash-flow constraint and letting the exogenous discount factor equal to the firm's borrowing rate.

\section{The Firm's Optimization Problem}

The Bellman equation for the optimization problem defined in the previous section can be obtained by an application of Itô's lemma and l'Hôpital's rule as follows:

$$
\rho V\left(K_{t}, B_{t}, \varepsilon_{t}\right)=\max _{I_{t}, N_{t}}\left(\pi\left(K_{t}, \varepsilon_{t}\right)-c\left(I_{t}, K_{t}\right)-r B_{t}+N_{t}+E_{t} \frac{d V}{d t}\right)
$$

where the maximization problem is subject to the inequality constraints defined in equations (2.5) and (2.6) and the term $E_{t} d V / d t$ is defined as follows:

$$
\begin{aligned}
\frac{E_{t} d V}{d t}= & V_{K}\left(K_{t}, B_{t}, \varepsilon_{t}\right)\left(I_{t}-\delta K_{t}\right)+V_{B}\left(K_{t}, B_{t}, \varepsilon_{t}\right) N_{t}+ \\
& V_{\varepsilon}\left(K_{t}, B_{t}, \varepsilon_{t}\right) \mu\left(\varepsilon_{t}, t\right)+\frac{1}{2} V_{\varepsilon \varepsilon}\left(K_{t}, B_{t}, \varepsilon_{t}\right) \sigma\left(\varepsilon_{t}, t\right)^{2}
\end{aligned}
$$

Equation (3.1) can be interpreted as a no-arbitrage condition on the value of the firm at time $t$. Given the exogenous discount factor $\rho$, the term on the left-hand side represents the required normal return on the firm's value. The term on the

\footnotetext{
${ }^{4}$ Foundations for firm's financial constraints of the type described in the text are usually given in terms of either adverse selection or moral hazard arguments. For instance, in the business finance literature this sort of constraints are implied in the works of Jensen and Meckling (1976) and Myers and Majluf (1984). In the asymmetric information literature in the works Stiglitz and Weiss (1981, 1983) and Greenwald, Stiglitz and Weiss (1984). More recently, the literature on the financial accelerator reviewed in Bernanke, Gertler and Gilchrist (1996) has emphasized the importance of the agency costs that arise in asymmetric information contexts. A typical feature of all this works is that the financial constraints depend in some form on the size of the firm's net worth or assets. In the present work, in order not to overburden notation, we have not made this assumption explicitely. We suppose, however, that it holds implicitely.
} 
right-hand side is the sum of two components, the instantaneous return to shareholders at time $t$, which is represented by the firm's cash-flow and follows from the firm's optimal choices of investment and new debt issue, and the expected capital gain on the firm's value. From equation (3.2) the expected capital gain on the firm's value is the sum of a component that depends on the firm's choices about the rate of physical capital accumulation and new debt issue, a component that depends on the drift of the stochastic state variable at time $t$ and a component that takes into account of the effects of uncertainty. ${ }^{5}$

In order to analyze the firm's optimization problem, we first note that in the presence of fixed costs of adjustment the choice of the optimal level of investment at time $t$ is made in two stages. The firm must first decide whether to invest or not to invest. Secondly, if it invests it must afford the fixed cost of capital adjustment and choose the optimal level of investment. To begin the analysis of the firm's optimization problem however its preferable to abstract from the firm's choice on whether to invest or not to invest, this allows to clarify some of the main features of firm's problem. ${ }^{6}$

For the purposes of the analysis it is useful to define the multipliers $q_{t}=$ $V_{K}\left(K_{t}, B_{t}, \varepsilon_{t}\right)$, representing the marginal value of an additional unit of physical capital stock at time $t$, and $q_{t}^{B}=V_{B}\left(K_{t}, B_{t}, \varepsilon_{t}\right)$, representing the marginal value of an additional unit of debt at time $t$. Following Hayashi (1982), $q_{t}$ is usually referred to as Tobin's marginal $q$ or as the shadow price of capital. We can similarly refer to $q_{t}^{B}$ as the shadow price of firm's debt.

Given the above definitions consider the value function $H_{t}=-c\left(I_{t}, K_{t}\right)+q_{t} I_{t}+$ $\left(1+q_{t}^{B}\right) N_{t}$ where we suppose that investment $I_{t}$ and new debt issue $N_{t}$ are held at their optimal values. The function $H_{t}$ is the sum of two terms, the first term, $-c\left(I_{t}, K_{t}\right)+q_{t} I_{t}$, can be interpreted as the value of investment at time $t$ net of the cost of adjustment, where each unit of investment is priced at its marginal value $q_{t}$. The second term, $\left(1+q_{t}^{B}\right) N_{t}$, represents the net return from the firm's financial choices. In each period of time, the value function $H_{t}$ and the normal return on the value of the firm are equal up to a constant term, therefore the firm's optimization problem can be studied using the value function $H_{t}$ as the objective.

The optimal values of investment and new debt issue are determined at every instant of time $t$ conditionally on the state variables. We will show that, similarly to the case of perfect financial markets, in the presence of credit constraints optimal investment is a non-decreasing function of the shadow price of capital $q_{t}$. In addition, we will show that the characterization of the investment function is sufficient to characterize the optimal function for new debt issue. This will follow from the consideration that when the liquidity constraints are not binding the firm is indif-

\footnotetext{
${ }^{5}$ The assumptions on the shape of the firm's short-run profit function and on the adjustment cost function imply that the firm's optimization problem is well defined and that its solution can be characterized with conventional arguments. An introduction to continuous-time stochastic dynamic programming can be found in Malliaris and Brock (1982), the approach in the text follows most closely Krylov (1980).

${ }^{6}$ One may suppose for example that the fixed cost $a_{0}$ is equal to 0 , alternatively one may suppose that a choice for investing has been made. Note that the latter choice is actually made by the firm conditionally on the information on the optimal value that would be obtained by affording the fixed cost of adjustment. We note also that the assumption of the existence of fixed costs of capital adjustment implies that investment at the firm's level can be model as an option. Interpretations of firm's investment as an option can be found in Dixit and Pindyck (1994) and Abel et. al. (1996).
} 
ferent as to the level of new debt issue and when the constraints are binding the firm is holding new debt issue at the upper bound $\bar{N}$.

Since the firm's maximization problem is subject to an inequality constraint on the amount of new debt issue and a non-negativity constraint on cash-flow, in each period of time $t$ at the optimal values of investment and new debt issue the following conditions must be satisfied:

$$
c_{I}\left(I_{t}, K_{t}\right) \leq q_{t}
$$

and:

$$
q_{t}^{B} \geq-\frac{q_{t}}{c_{I}\left(I_{t}, K_{t}\right)}
$$

The structure of the firm's optimization problem implies that either both the constraint on new debt issue and the cash-flow constraint are binding or that both constraints are not binding, the intermediate cases when only one constraint is binding can be ruled out.

When both the credit constraint and the cash-flow constraint are not binding equations (3.3) and (3.4) hold with equality. Equation (3.3) in this case states that at the optimal level of investment the marginal cost of additional units of the physical capital stock $c_{I}\left(I_{t}, K_{t}\right)$ must be equal to its marginal value $q_{t}$. Equation (3.4) states that the marginal value of an additional unit of debt $q_{t}^{B}$ must be equal to -1 . The equality between the marginal cost and the marginal value of capital has the usual interpretation. In order to interpret the second condition, note that by construction of the firm's optimization problem each unit of debt in the long-run is repaid as interest payment at a constant interest rate $r$. Given the exogenous discount factor $\rho$ the present discounted value of such payments is $-r / \rho$ which is greater than or equal to -1 , since in the case of imperfect financial markets we are considering we are assuming that $r \leq \rho$. The condition therefore states that there are additional provisions over debt repayment, that must be afforded by the firm for each marginal additional unit of debt. We will clarify below that these provisions depend on the possibility financing investment activity through external debt and are related to the firm's expectations over future financial conditions. In any event the condition implies that when the financial constraints are not binding the firm is indifferent as to the level of new debt issue, since each additional marginal unit of debt in the long run gets repaid. ${ }^{7}$

In order to interpret equations (3.3) and (3.4) when the liquidity constraints are binding define the multipliers related to the constraint on new debt issue and on the cash-flow constraint $\partial H_{t} / \partial \bar{N}$ and $\partial H_{t} / \partial \varphi$, where $\varphi=0$ denotes the lower bound on cash-flow implied by the non-negativity condition. The multiplier $\partial H_{t} / \partial \bar{N}$ represents the shadow price of an additional marginal unit of new debt at time $t$ and the multiplier $\partial H_{t} / \partial \varphi$ represents the shadow price of an additional marginal unit of cash-flow at time $t$. Both multipliers are non-negative and they are equal to zero when the liquidity constraints are not binding, since in this latter case there are no additional gains for the firm from relaxing the financial constraints.

\footnotetext{
${ }^{7}$ In the case of perfect financial markets, $r=\rho$ and this implies that $-r / \rho=-1$ and therefore that there are no provisions over debt repayment that must be afforded by the firm for each additional marginal unit of debt.
} 
When both the financial constraints are binding, then equation (3.3) implies that at the optimal path for investment the marginal value of an additional unit of physical capital stock is above its marginal cost. Since marginal costs are an increasing function of $I_{t}$, the firm would like to increase investment so as to equate marginal costs with marginal benefits but it runs in an upper bound, which is determined in relation to the constraint on new debt issue and to the non-negativity constraint on cash-flow. The analysis of the firm's optimization problem reveals that in this case $q_{t}-c_{I}\left(I_{t}, K_{t}\right)=c_{I}\left(I_{t}, K_{t}\right) \partial H_{t} / \partial \varphi$, such that the difference between the marginal value of the capital stock and its marginal cost is equal to the shadow price of an additional marginal unit of cash-flow times the marginal cost of investment. This latter quantity represents the shadow value of an additional marginal unit of investment obtained by relaxing the cash-flow constraint. Given that the marginal value of the physical capital stock is greater than its marginal cost, the firm would gain from relaxing the financial constraints, since this would make additional marginal investment possible, and condition (3.3) represents this gain.

Similar considerations hold for condition (3.4), in this case it is possible to show that $q_{t}^{B}=-1+\partial H_{t} / \partial \bar{N}-\partial H_{t} / \partial \varphi$, such that once the effects of debt repayment have been taken into account there are additional provisions over debt repayment that affect the marginal value of an additional unit of debt. These marginal provisions are equal to the net marginal gain that would be obtained by relaxing the constraint on new debt issue, once the effects of the marginal additional investment that would in this way be allowed through the additional marginal available cash-flow are subtracted from the computation. ${ }^{8}$

\section{The Investment Function and the Value of the Firm}

In order to derive the optimal investment function, we recall first that in the presence of fixed costs of capital adjustment the firm optimization problem can be decomposed in two steps, the decision on whether to invest and thus incur in the fixed cost of adjustment and the decision on the optimal amount of investment. When the firm is investing there are moreover two situations of interest, the case where the financial constraints are not binding and the case where they are binding. We develop the analysis of the investment function considering first the firm's choice of whether or not to invest, assuming that the financial constraints are not binding, and then describe the behavior of the function in the range of binding financial constraints.

The decision on whether or not to invest is made by the firm comparing the value that would be obtained when not investing with the value that would result from investing and affording the fixed cost of capital adjustment. When the firm is not investing $I_{t}=0$ and the firm does not run in any cost of capital adjustment such that $c\left(0, K_{t}\right)=0$. Since the financial constraints in this case are not binding, from the analysis of the previous section it follows that $1+q_{t}^{B}=0$. Hence, when the firm is not investing $H_{t}=0$ and this in turn implies that at time $t$ the firm would be

\footnotetext{
${ }^{8} \mathrm{~A}$ more extensive development of these points is contained in the appendix, where a formal solution to the firm's optimization problem and formal derivations of the multipliers $\partial H_{t} / \partial \bar{N}$ and $\partial H_{t} / \partial \varphi$ are provided.
} 
willing to undertake a positive investment policy only as long as $H_{t} \geq 0$.

If the firm is investing instead and the financial constraints are not binding, it can be shown that investment is a smooth function of marginal $q$. The results described in the previous section imply that in this case condition (3.3) holds with equality and therefore the marginal cost of investment is equal to the marginal value of the physical capital stock. The assumptions on the adjustment cost function imply that on the positive investment range the marginal cost function is increasing, it follows that optimal investment at time $t$ is an increasing function of the marginal value of the physical capital stock $q_{t}$ :

$$
I\left(q_{t}\right)=c_{I}^{-1}\left(q_{t}\right)
$$

where for simplicity the dependence of optimal investment on the level of the physical capital stock at time $t$ has been omitted and by an application of the implicit function theorem $I_{q}\left(q_{t}\right)=1 / c_{I I}\left(I\left(q_{t}\right), K_{t}\right) \geq 0 .{ }^{9}$

When the firm is investing and the credit constraints are not binding condition (3.4) also holds with equality so that $1+q_{t}^{B}=0$. Equation (4.1) then implies that the value function $H_{t}$ is an increasing and convex function of shadow price of capital:

$$
H\left(q_{t}\right)=q_{t} I\left(q_{t}\right)-c\left(I\left(q_{t}\right), K_{t}\right)
$$

where $H_{q}\left(q_{t}\right)=I\left(q_{t}\right) \geq 0$ and $H_{q q}=I_{q}\left(q_{t}\right) \geq 0$, we note for later use that the shape of the value function also implies that $\lim _{q_{t} \rightarrow 0^{+}} H\left(q_{t}\right)=-a_{0}$ such that as the shadow price of physical capital converges to 0 from above the value taken by the value function converges to the opposite of the fixed cost of capital adjustment.

The firm will take a positive investment policy at time $t$ and therefore afford the fixed cost of adjustment, only as long as $H\left(q_{t}\right) \geq 0$. By equation (4.2) this condition requires the shadow price of capital to be greater than or equal to the average adjustment cost, such that $q_{t} \geq c\left(I\left(q_{t}\right), K_{t}\right) / I\left(q_{t}\right)$. Since in equilibrium $q_{t}$ is equal to the marginal cost of adjustment, $c_{I}\left(I\left(q_{t}\right), K_{t}\right)$, in the presence of fixed costs of adjustment the firm will find it worth to undertake investment activity only as long as the marginal costs of adjustment are greater than or equal to the average costs.

Since the value function is increasing and continuous, we suppose therefore that in every time period there exist a value $\widetilde{q}$ of the shadow price of physical capital, such that $H(\widetilde{q})=0$ or $\widetilde{q}=c\left(I(\widetilde{q}), K_{t}\right) / I(\widetilde{q})$ and the firm is indifferent between investing and not investing. For values of $q_{t}<\widetilde{q}$ the firm will find it optimal not to invest, since the fixed costs component imply costs of physical capital adjustment that are greater then the expected present discounted value of additional investment, while for $q_{t}>\widetilde{q}$ the firm will find it worth to adopt a positive investment policy. ${ }^{10}$

To complete the analysis we need to characterize the case when the firm is adopting a positive investment policy and the financial constraints are binding. In this case the constraint on new debt issue holds with equality, such that $N_{t}=\bar{N}$, and

\footnotetext{
${ }^{9}$ In equation (4.1) we are implicitely assuming that the marginal investment cost function is invertible. We will keep to this assumption throughout the analysis.

${ }^{10}$ When the fixed costs of capital adjustment $a_{0}$ are equal to $0, \widetilde{q}=0$ and therefore the condition $q_{t}>\widetilde{q}$ is satisfied as long as $q_{t}>0$. For positive values of $a_{0}$ the fixed cost of adjustment are spread over each unit of additional investment at time $t$, when the firm decides to invest and therefore to afford such a cost.
} 
this in turn implies that investment is at an upper bound $I_{t}=\bar{I}>0$, because costs of adjustment are increasing in $I_{t}$ in the positive investment range and the cashflow constraint implies that $c\left(\bar{I}, K_{t}\right)=\pi\left(K_{t}, \varepsilon_{t}\right)-r B_{t}+\bar{N}$. Since the investment function defined in equation (4.1) is an increasing function of $q_{t}$, the investment upper bound $\bar{I}$ defines a value $\bar{q}$ such that $I\left(q_{t}\right)=\bar{I}$ for $q_{t} \geq \bar{q}$. We summarize the main findings regarding the firm's value function and the firm's investment function in the following propositions.

Proposition 4.1: In the presence of fixed costs of adjustment and financial constraints investment is a non-decreasing function of $q_{t}$. In each time period $t$ there exist a value $\widetilde{q}=c\left(I(\widetilde{q}), K_{t}\right) / I(\widetilde{q})$ such that $I\left(q_{t}\right)=0$ for $q_{t}<\widetilde{q}$ and $I\left(q_{t}\right) \geq 0$ for $q_{t} \geq \widetilde{q}$. Moreover, there exist a value $\bar{q}$ such that $c\left(I(\bar{q}), K_{t}\right)=\pi\left(K_{t}, \varepsilon_{t}\right)-r B_{t}+\bar{N}$ and for all $q_{t} \geq \bar{q}$ investment $I\left(q_{t}\right)$ is at an upper bound $\bar{I}=I(\bar{q})$. In the range $\widetilde{q} \leq q_{t} \leq \bar{q}$ investment at time $t$ is defined by equation (4.1) as $I\left(q_{t}\right)=c_{I}^{-1}\left(q_{t}\right)$ an increasing function of $q_{t}$.

Proof: Appendix.

A graphical illustration of the investment function is reproduced in Figure 1 for the case where the slope of $I\left(q_{t}\right)$ is decreasing in $q_{t}$ in the range $\widetilde{q} \leq q_{t} \leq \bar{q}$, note that the curvature of the investment function depends on additional assumptions concerning the shape of the adjustment costs function.

Proposition 4.2: In the presence of fixed costs of adjustment and credit constraints the value function is an increasing function of $q_{t}$. In each time period $t$ there exist a value $\widetilde{q}=c\left(I(\widetilde{q}), K_{t}\right) / I(\widetilde{q})$ such that $H\left(q_{t}\right)=0$ for $q_{t}<\widetilde{q}$ and $H\left(q_{t}\right) \geq 0$ for $q_{t} \geq \widetilde{q}$. Moreover, there exist a value $\bar{q}$ such that $c\left(I(\bar{q}), K_{t}\right)=$ $\pi\left(K_{t}, \varepsilon_{t}\right)-r B_{t}+\bar{N}$ and for all $q_{t} \geq \bar{q}$ investment $I\left(q_{t}\right)$ is at an upper bound $\bar{I}=I(\bar{q})$ and $H\left(q_{t}\right)=q_{t} \bar{I}-c\left(\bar{I}, K_{t}\right)+\left(1+q_{t}^{B}\right) \bar{N}$. In the range $\widetilde{q} \leq q_{t} \leq \bar{q}$ the value function is $H\left(q_{t}\right)=q_{t} I\left(q_{t}\right)-c\left(I\left(q_{t}\right), K_{t}\right)$ an increasing and convex function of $q_{t}$ with $I\left(q_{t}\right)=c_{I}^{-1}\left(q_{t}\right)$, while for all $q_{t} \geq \bar{q}$ it holds that $H\left(q_{t}\right) \leq q_{t} c_{I}^{-1}\left(q_{t}\right)-c\left(c_{I}^{-1}\left(q_{t}\right), K_{t}\right)$.

\section{Proof: Appendix.}

The last part of proposition 4.2 states that for $q_{t} \geq \bar{q}$ the value function $H\left(q_{t}\right)$ is lower than or equal to the value that would be attained in the absence of financial constraints. Note that throughout the analysis we have assumed that $\widetilde{q} \leq \bar{q}$, this condition however is not always required. The value function is depicted graphically in Figure 2. 
Figure 1: The Firm's Investment Function

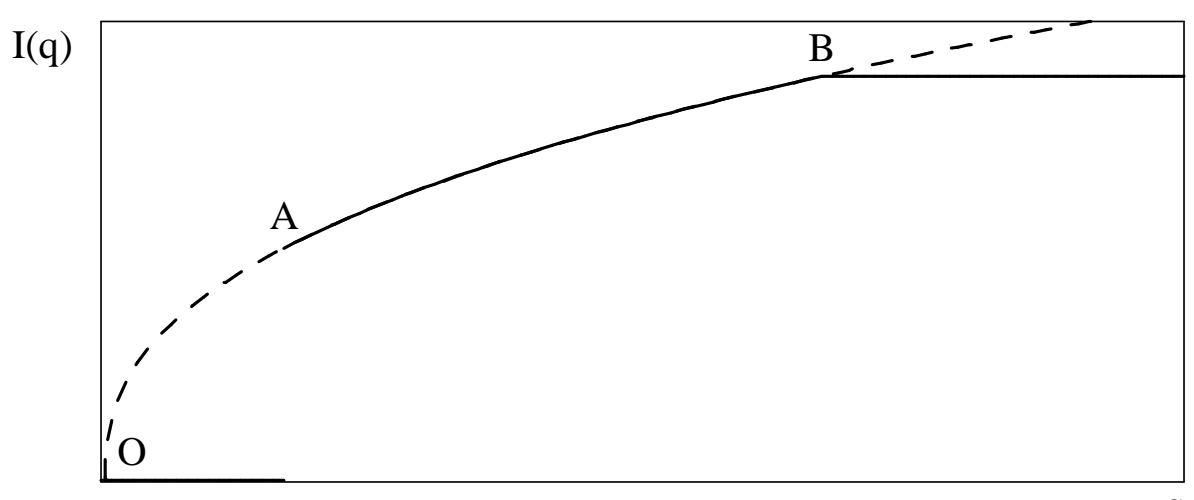

q

Note: The bold line depicts the firm's investment function $I(q)$ as a function of Tobin's marginal $q$. The point $A$ shows the value $\widetilde{q}$ that makes the firm indifferent between investing and not investing. The point $B$ shows the value $\bar{q}$ that makes firm's investment equal to the upper bound $\bar{I}$. The dashed line depicts the firm's investment function for the case of perfect financial markets and convex costs of physical capital adjustment $\left(a_{0}=0\right)$.

Figure 2: The Firm's Value Function

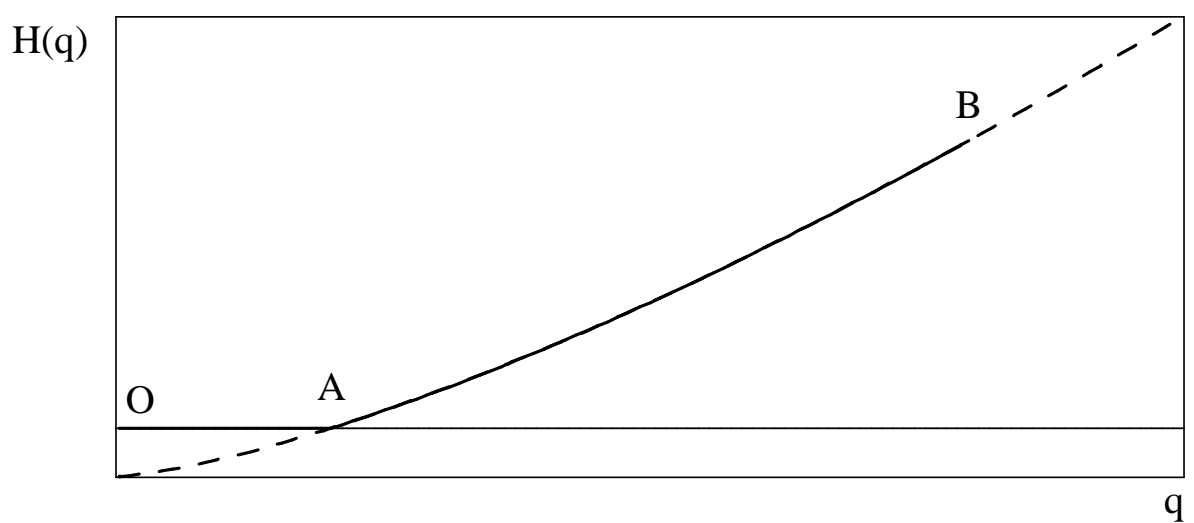

Note: The bold line depicts the firm's value function $H(q)$ as a function of Tobin's marginal $q$. The point $A$ shows the value $\widetilde{q}$ that makes the firm indifferent between investing and not investing. The point $B$ shows the value $\bar{q}$ that makes firm's investment equal to the upper bound $\bar{I}$. The dashed line depicts the firm's value function for the case of perfect financial markets and convex costs of physical capital adjustment $\left(a_{0}=\right.$ $0)$. 
Finally, we note that since in each period of time the costs of capital adjustment are a decreasing function of the physical capital stock $K_{t}$ and firm's profits are an increasing function of $K_{t}$, for each given level of the upper bound $\bar{N}$ on new debt issue the investment upper bound $\bar{I}$ is increasing in $K_{t}, \partial \bar{I} / \partial K_{t}=\left(\pi_{K}\left(K_{t}, \varepsilon_{t}\right)-\right.$ $\left.c_{K}\left(\bar{I}, K_{t}\right)\right) / c_{I}\left(\bar{I}, K_{t}\right) \geq 0$. Similarly, since firm's profits are an increasing function of the stochastic state variable $\varepsilon_{t}$, the investment upper bound $\bar{I}$ is increasing in $\varepsilon_{t}$. In addition, since interest payments are an increasing function of firm's debt stock $B_{t}$, the investment upper bound $\bar{I}$ is decreasing in $B_{t}, \partial \bar{I} / \partial B_{t}=-r / c_{I}\left(\bar{I}, K_{t}\right) \leq 0$. It is also straightforward to show that $\partial \bar{I} / \partial \bar{N}=1 / c_{I}\left(\bar{I}, K_{t}\right) \geq 0$ and that since the capital adjustment cost function is convex $\partial^{2} \bar{I} / \partial \bar{N}^{2} \leq 0$ such that for each level of the physical capital stock the investment upper bound is an increasing and concave function of the upper bound on new debt issue. Note also that $\lim _{\bar{N} \rightarrow+\infty} \bar{I}=+\infty$. These conditions can be easily interpreted considering that $c_{I}\left(\bar{I}, K_{t}\right)$ is the marginal cost of installing one more unit of capital when the financial constraints are binding and the level of the physical capital stock is $K_{t}$. The locus of the relation between the upper bounds on investment and new debt issue is illustrated in Figure 3.

Figure 3: The Investment-New Debt Upper Bounds Locus

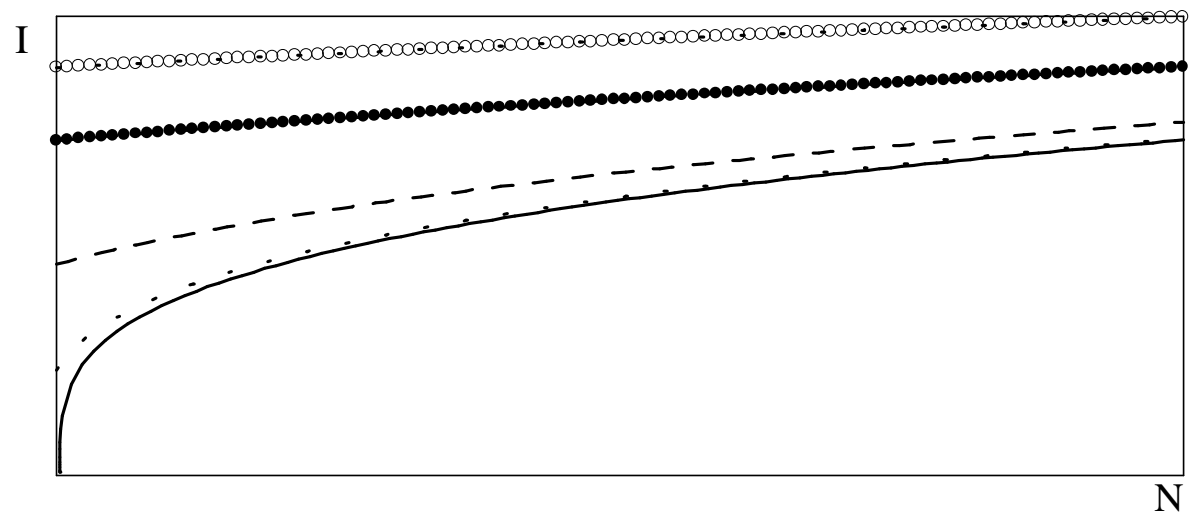

Note: Each level curve corresponds to a different level of the firm's physical capital stock or of the stochastic state variable or of the firm's debt stock.

\section{The External Finance Premium and the Shadow Price of Capital}

In this section we provide a description of the dynamics of the shadow price of capital $q_{t}$ and show how its value in each time period is determined by the firm's marginal profitability and by present and future financial constraints. We show in particular that the presence of financial constraints determines a positive external finance premium on the shadow price of capital. 
Consider the Bellman equation for the firm's optimization problem defined in equations (3.1) and (3.2) and suppose that firm's investment $I_{t}$ and new debt issue $N_{t}$ are at their optimal values. Differentiating the Bellman equation with respect to $K_{t}$ and noting that $q_{t}=V_{K}\left(K_{t}, B_{t}, \varepsilon_{t}\right)$ implies $q_{K t}=V_{K K}\left(K_{t}, B_{t}, \varepsilon_{t}\right), q_{B t}=$ $V_{B K}\left(K_{t}, B_{t}, \varepsilon_{t}\right), q_{\varepsilon t}=V_{\varepsilon K}\left(K_{t}, B_{t}, \varepsilon_{t}\right)$ and $q_{\varepsilon \varepsilon t}=V_{\varepsilon \varepsilon K}\left(K_{t}, B_{t}, \varepsilon_{t}\right)$, such that by an application of Itô's lemma $E_{t} d q / d t=q_{K t}\left(I_{t}-\delta K_{t}\right)+q_{B t} N_{t}+q_{\varepsilon t} \mu\left(\varepsilon_{t}, t\right)+\frac{1}{2} q_{\varepsilon \varepsilon t} \sigma\left(\varepsilon_{t}, t\right)^{2}$, we get the following equality for the shadow price of capital:

$$
(\rho+\delta) q_{t}=\pi_{K}\left(K_{t}, \varepsilon_{t}\right)-c_{K}\left(I_{t}, K_{t}\right)+\theta\left(K_{t}, B_{t}, \varepsilon_{t}\right)+\frac{E_{t} d q}{d t}
$$

where the function $\theta\left(K_{t}, B_{t}, \varepsilon_{t}\right)$ is defined as follows:

$$
\theta\left(K_{t}, B_{t}, \varepsilon_{t}\right)=\frac{q_{t}-c_{I}\left(I_{t}, K_{t}\right)}{c_{I}\left(I_{t}, K_{t}\right)}\left(\pi_{K}\left(K_{t}, \varepsilon_{t}\right)-c_{K}\left(I_{t}, K_{t}\right)\right)
$$

Equation (5.1) can be interpreted as a no-arbitrage condition on the shadow price of capital $q_{t}$. The term on the left hand side represents the required normal return on the shadow price $q_{t}$, which includes a provision for physical capital depreciation. The term on the right hand side is composed of three components, the marginal profitability of the physical capital stock $\pi_{K}\left(K_{t}, \varepsilon_{t}\right)-c_{K}\left(I_{t}, K_{t}\right)$, an allowance for the financial constraints $\theta\left(K_{t}, B_{t}, \varepsilon_{t}\right)$, and the capital gain $E_{t} d q / d t$.

In the first component, the term $-c_{K}\left(I_{t}, K_{t}\right)$ is a provision for the costs of physical capital adjustment and following recent contributions by Abel and Eberly (1996, 1999) we can refer to this term as to an irreversibility premium, note that by assumption $-c_{K}\left(I_{t}, K_{t}\right) \geq 0$. This term captures the increases in the firm's profitability that arise from marginal additions to the physical capital stock, as a consequence of the gains in the efficiency of the process of physical capital adjustment.

The term $\theta\left(K_{t}, B_{t}, \varepsilon_{t}\right)$ is the allowance for the financial constraints and we refer to this term as to an external finance premium. The results in the previous sections imply that $\theta\left(K_{t}, B_{t}, \varepsilon_{t}\right) \geq 0$ in all periods of time $t$ and this relation holds with equality only in periods of time when the financial constraints are not binding. The external finance premium arises in the presence of financial constraints, because when the constraints are binding there is a positive value to each additional marginal unit of the physical capital stock, which is given by the difference between the shadow price and the marginal cost of capital.

It is interesting to note that the marginal profitability of the physical capital stock and the external finance premiums are somehow related. The profitability gains that follow from additional marginal units of the physical capital stock at time $t$, imply that additional investment can be afforded when the constraints are binding and marginal units of the physical capital stock become available to the firm.

The shadow price of capital can be further characterized considering that equation (5.1) is a stochastic partial differential equation in $q_{t}$, whose solution can be obtained applying an important result in the theory of stochastic calculus, known as Feynman-Kac theorem:

$$
q_{t}=E_{t} \int_{t}^{+\infty}\left(\pi_{K}\left(K_{\tau}, \varepsilon_{\tau}\right)-c_{K}\left(I_{\tau}, K_{\tau}\right)+\theta\left(K_{\tau}, B_{\tau}, \varepsilon_{\tau}\right)\right) e^{-(\rho+\delta)(\tau-t)} d \tau
$$


Equation (5.3) states the shadow price of capital at time $t$ is equal to the expected present discounted value of the sum of the marginal profitability of capital and of the external finance premium. ${ }^{11}$

Since the external finance premium $\theta\left(K_{\tau}, B_{\tau}, \varepsilon_{\tau}\right)$ is greater than or equal to zero in each period $\tau \geq t$, equation (5.3) shows that in each period of time the shadow value of capital $q_{t}$ is greater than or equal to the value that would obtain in the case of perfect financial markets. In the presence of financial constraints, the firm anticipates future constraints and gives a greater value to current investment in each period $t$. Since firm's investment is a non-decreasing function of the shadow price of capital $q_{t}$, this implies that in each period of time investment is positively related to future financial constraints. The definition of the external finance premium shows that this effect arises because current marginal additions to the physical capital stock, allow marginal additional investment to take place in future periods characterized binding financial constraints. The definition of $\theta\left(K_{\tau}, B_{\tau}, \varepsilon_{\tau}\right)$ provided in equation (5.2) interestingly also implies that the external finance premium is positively related to the values $q_{\tau}$ of the firm's future marginal $q$ for $\tau \geq t$. The presence of financial constraints results therefore in a positive feedback from future to current firm's marginal profitability of investment. In each period of time $t$, this effect holds for future periods $\tau \geq t$ characterized by binding financial constraints. ${ }^{12}$

These results should be compared with the analogous findings in the consumption function literature, of a negative effect of future financial constraints on current consumption with a correspondingly positive effect on current household savings. ${ }^{13}$

In order to complete the description of the properties of the shadow price of capital, we note that an alternative interpretation of the external finance premium can be obtained by rewriting the dynamic equation for $q_{t}$ as $(\rho+\delta) q_{t}-E_{t} d q / d t=$ $\pi_{K}\left(K_{t}, \varepsilon_{t}\right)-c_{K}\left(I_{t}, K_{t}\right)+\theta\left(K_{t}, B_{t}, \varepsilon_{t}\right)$. In this version of the stochastic partial differential equation for $q_{t}$ the term on the left-hand side represents the shadow marginal user cost of physical capital, which is obtained subtracting from the required normal return $(\rho+\delta) q_{t}$ on the shadow price of capital $q_{t}$ the expected capital gain $E_{t} d q / d t$ and where the normal return includes a provision for physical capital depreciation. The term on the right-hand side is the sum of three components, the marginal profitability of capital, the provision for irreversibility and the external finance premium. Note that both the provision for irreversibility and the external finance premium raise marginal user cost of capital at each time $t$. This version of equation (5.1) is also usually referred to as a Euler equation and turns out to be particularly useful in the context of econometric estimation.

\footnotetext{
${ }^{11}$ A formal derivation of the Feynman-Kac theorem is provided in Karatzas and Shreve (1988, pp. 267 ss.).

${ }^{12}$ The solution for the firm's marginal $q$ provides a formalization to the findings concerning the effects of credit constraints on investment of the pre 1990s empirical literature, that are reviewed in Chirinko (1993). An illustration of a positive feedback effect from future to current marginal firm's profitability of invesment in the presence of financial constraints, similar to the one described in the present work, has been provided in a simplified model by Kiyotaki and Moore (1997).

${ }^{13}$ For household models the effects of expectations on future liquidity constraints on current consumption and saving are described in Deaton $(1991,1992)$.
} 


\section{The Shadow Price of Firm's Debt}

Finally, we provide a characterization of the shadow price of firm's debt $q_{t}^{B}$ and a description of the external finance premium in relation to this quantity, this will allow to provide a support for the condition stated at the beginning of the analysis that the firm must issue debt at a borrowing rate that is lower than or equal to the exogenous discount rate and to provide some additional insights on the firm's optimization problem.

We proceed in a similar way as for the shadow price of capital. Differentiating the Bellman equation defined in equations (3.1) and (3.2) with respect to $B_{t}$ and noting that $q_{t}^{B}=V_{B}\left(K_{t}, B_{t}, \varepsilon_{t}\right)$ implies $q_{K t}^{B}=V_{K B}\left(K_{t}, B_{t}, \varepsilon_{t}\right), q_{B t}^{B}=V_{B B}\left(K_{t}, B_{t}, \varepsilon_{t}\right)$, $q_{\varepsilon t}^{B}=V_{\varepsilon B}\left(K_{t}, B_{t}, \varepsilon_{t}\right)$ and $q_{\varepsilon \varepsilon t}^{B}=V_{\varepsilon \varepsilon B}\left(K_{t}, B_{t}, \varepsilon_{t}\right)$ such that by an application of Itô's lemma $E_{t} d q^{B} / d t=q_{K t}^{B}\left(I_{t}-\delta K_{t}\right)+q_{B t}^{B} N_{t}+q_{\varepsilon t}^{B} \mu\left(\varepsilon_{t}, t\right)+\frac{1}{2} q_{\varepsilon \varepsilon t}^{B} \sigma\left(\varepsilon_{t}, t\right)^{2}$, we get the following equality for the shadow price of firm's debt:

$$
\rho q_{t}^{B}=-r+\theta^{B}\left(K_{t}, B_{t}, \varepsilon_{t}\right)+\frac{E_{t} d q^{B}}{d t}
$$

where the function $\theta^{B}\left(K_{t}, B_{t}, \varepsilon_{t}\right)$ is defined as:

$$
\theta^{B}\left(K_{t}, B_{t}, \varepsilon_{t}\right)=-\frac{q_{t}-c_{I}\left(I_{t}, K_{t}\right)}{c_{I}\left(I_{t}, K_{t}\right)} r
$$

Equation (6.1) can be interpreted as a no-arbitrage condition on the shadow price of firm's debt. The left-hand side represents the normal return on the shadow price of debt at time $t$. The right-hand side is composed of three terms the marginal interest cost $r$ of an additional unit of debt at time $t$, a provision for external finance $\theta^{B}\left(K_{t}, B_{t}, \varepsilon_{t}\right)$ and the capital gain $E_{t} d q^{B} / d t$.

Equation (6.2) shows that the provision for external finance is lower than or equal to zero in each time period so that $\theta^{B}\left(K_{t}, B_{t}, \varepsilon_{t}\right) \leq 0$ for all $t$ and this equation holds with equality only in periods of time where the financial constraints are not binding. In particular, according to $(6.2) \theta^{B}\left(K_{t}, B_{t}, \varepsilon_{t}\right)$ is equal to the marginal loss to share-holders of an additional marginal unit of debt at time $t$. The analysis in the previous sections shows that this marginal loss results from lower investment and therefore it is proportional to the factor $q_{t}-c_{I}\left(I_{t}, K_{t}\right)$. The latter represents the marginal gain from a marginal additional unit of investment at time $t$, a term which is positive given binding financial constraints. Since additional debt at time $t$ however entails greater interest payments and therefore lower investments by a factor equal to $-r / c_{I}\left(I_{t}, K_{t}\right)$, the marginal value of additional debt at time $t$ is lower than or equal to zero.

In order to obtain the shadow price of firm's debt $q_{t}^{B}$ we note that, similarly to the shadow price of capital, equation (6.1) is a stochastic partial differential equation that can be solved applying the Feynman-Kac theorem. The result is the following:

$$
q_{t}^{B}=-\frac{r}{\rho}+E_{t} \int_{t}^{+\infty} \theta^{B}\left(K_{\tau}, B_{\tau}, \varepsilon_{\tau}\right) e^{-\rho(\tau-t)} d \tau
$$

Equation (6.3) shows that the shadow price of firm's debt is composed of two 
terms. The first term $-r / \rho$ is the expected present discounted value of interest payments of an additional unit of debt at time $t$. Since the firm's borrowing rate $r$ is lower than the exogenous discount factor $\rho$, this term is greater than or equal to -1 . The second term represents the additional provisions on the firm's debt that are related to the current and future borrowing constraints. Since the external finance premium $\theta^{B}\left(K_{\tau}, B_{\tau}, \varepsilon_{\tau}\right)$ is lower than or equal to zero in each period $\tau \geq t$, this term is also lower than or equal to zero. This additional provisions represent the expected future marginal costs of an additional unit of debt at time $t$, that depend on the marginal reductions of the level of investment in physical capital, that occur in the presence of binding constraints as a consequence of the marginal increase in the firm's interest payments.

Similarly to the analysis of the shadow price of physical capital, the definition of the provision for external finance implies a negative feedback from the values $q_{\tau}$ of the future marginal $q$ for $\tau \geq t$ and the shadow price of firm's debt. In each period of time $t$ this effect holds in relation to future periods $\tau \geq t$ with binding financial constraints.

We conclude by noting that the dynamic equation for the shadow price of firm's debt can be rewritten as $\rho q_{t}^{B}-E_{t} d q^{B} / d t=-r+\theta^{B}\left(K_{t}, B_{t}, \varepsilon_{t}\right)$. The term on the left hand side of this expression can be thought of as a shadow marginal borrowing rate for the firm at time $t$, the right hand side shows that this marginal rate is equal to the sum of the interest payments on firm's debt and to the premium provisions of each additional unit of debt that arise when the financial constraints are binding.

\section{Conclusions}

The previous sections have presented a model of firm's investment under uncertainty characterized by financial market imperfection and have analyzed the effects of credit constraints on firm's investment. The analysis shows that similarly to the case of perfect financial markets in each time period there is a positive relation between firm's investment and the firm's shadow value of capital or marginal $q$. However, in the presence of financial constraints there is an upper bound to firm's investment and in each time period investment is constant for values of the firm's marginal $q$ greater than or equal to a given threshold value. This follows since in each period of time the amount of investment is limited by the firm's borrowing capabilities.

The paper shows that in the presence of financial constraints the firm's marginal $q$ is defined as the sum of the firm's expectations about future profitability and of an external finance premium representing the firm's expectations about future financial conditions. With financial market imperfections in each time period the firm's marginal $q$ is greater than in the case of perfect financial markets because marginal additions to the physical capital stock make additional marginal investment possible in periods when the financial constraints are binding.

The papers presents also some results concerning the relation between the firm's financial structure and the shadow price of firm's debt and shows that in the presence of financial market imperfections the shadow price of firm's debt is the sum of a term representing the interest payments on each marginal unit of debt and of a provision for external finance. The shadow cost of firm's debt is greater than in the case of perfect financial markets and the firm's financial structure has an effect on firm's investment since additional marginal units of debt are followed by greater

www.economics-ejournal.org 
interest payments and therefore imply lower levels of investment when the financial constraints are binding.

These results suggests several directions for further research, we note first that financial constraints have been modeled in a highly stylized way, assuming a constant borrowing rate and imposing an upper bound on the amount of debt that the firm can issue in each time period. It might therefore be interesting to analyze the consequences of alternative assumptions, the borrowing rate for example could be modeled as a function of the firm's debt position, as it has previously been done in studies of the consumption function. In this field, it would be moreover particularly interesting to study the behavioral foundations of financial markets imperfections. In addition, the relation between firm's financial structure and investment should be analyzed further.

The results presented in the paper are also interesting for their implications for the econometric analysis of the investment function. We note, in particular, that a widely used approach in this context, is to study the sensitivity of estimates of the response of firm's investment to cash flow to different financial conditions. Following the contributions of Fazzari, Hubbard and Petersen (1988), Hoshi, Kashyap and Scharfstein (1991), Bond and Meghir (1994) and Gilchrist and Himmelberg (1995) among others, in several studies an excess sensitivity of firm's investment to cashflow is taken as evidence of binding financial constraints. The main findings of this literature have however been questioned in recent studies by Kaplan and Zingales (1997) and Gomes (2001), were it is claimed that the that the results of the empirical estimations may be distorted by measurement errors.

The findings presented in this paper provide some insights that could inform further study in this field. In particular, the analysis in the paper suggests that in order to measure accurately the relationship between firm's investment and financial constraints one should construct measures of expected future financial conditions at the firm's level and use them in regressions of firm's investment on marginal $q$.

Finally, we note that the paper presents results that allow to express the firm's marginal $q$ in the traditional form of a Euler equation, the credit constraints in this case show up as a premium on the marginal user cost of physical capital which we call external finance premium. Following previous studies an interesting field of research would thus be to estimate versions of the Euler equation that allow to identify the different structural components of the model and in particular the contributions financial constraints to the user cost of capital. 


\section{Appendix - Proofs of Propositions}

We provide here some additional mathematical details for the results stated in the paper as well as formal proofs of the main propositions, limiting the analysis to the statements that have not received already a formal analysis in the main text. In order to provide some preliminary results we begin with the analysis of the firm's optimization problem defined in equations (3.1) and (3.2).

Following the analysis already introduced in section 3 consider the value function $H_{t}=-c\left(I_{t}, K_{t}\right)+q_{t} I_{t}+\left(1+q_{t}^{B}\right) N_{t}$, where $q_{t}=V_{K}\left(K_{t}, B_{t}, \varepsilon_{t}\right)$ represents the shadow price of the physical capital stock at time $t$ and $q_{t}^{B}=V_{B}\left(K_{t}, B_{t}, \varepsilon_{t}\right)$ the shadow price of firm's debt at time $t$, and note that the firm's optimization problem at time $t$ can be rewritten as:

$$
H\left(q_{t}\right)=\max _{I_{t}, N_{t}}\left(-c\left(I_{t}, K_{t}\right)+q_{t} I_{t}+\left(1+q_{t}^{B}\right) N_{t}\right)
$$

where the maximization is subject to the financial constraint on new debt issue (2.5) and to the cash-flow constraint (2.6).

The structure of the optimization problem implies that the optimal values for investment $I_{t}$ and new debt issue $N_{t}$ are defined as functions of the shadow price of capital $q_{t}$, this in turn implies that the firm value function is also defined as a function of $q_{t}$. In (A.1) we do not consider explicitly the dependence of the value function on the shadow price of firm's debt $q_{t}^{B}$ and on the financial constraints only for simplicity of notation, we clarify however these dependences during the course of the analysis.

The presence of fixed costs of adjustment imply that the firm's optimization problem must be decomposed in two stages, the decision on whether or not to invest and incur in the fixed cost of physical capital adjustment and the decision on the optimal amount of investment. In order to describe the solution of the problem we begin with the analysis of the second stage, assuming therefore that a decision to invest has been made.

Define with $\mu_{1}=\partial H\left(q_{t}\right) / \partial \bar{N}$ the Lagrange multiplier relating to the constraint on new debt issue and with $\mu_{2}=\partial H\left(q_{t}\right) / \partial \varphi$ the Lagrange multiplier relating to the cash-flow constraint, where $\varphi=0$ represents the level of the cash-flow constraint. The structure of the firm's optimization problem implies that that $\mu_{1}=0$ when the constraint on new debt issue is not binding and that $\mu_{2}=0$ when the cash-flow constraint is not binding. There are however only two cases of interest, the case when both constraints are binding and the case when both are not binding.

The first order conditions for the optimization problem (A.1) are:

$$
q_{t}=\left(1+\mu_{2}\right) c_{I}\left(I_{t}, K_{t}\right)
$$

and:

$$
q_{t}^{B}=-1+\mu_{1}-\mu_{2}
$$

In addition, the following complementary slackness conditions must hold at an 
optimum:

$$
\mu_{1}\left(N_{t}-\bar{N}\right)=0
$$

where $\mu_{1} \geq 0$ and by the constraint on the firm's new debt issue $N_{t}-\bar{N} \leq 0$ and:

$$
\mu_{2}\left(\pi\left(K_{t}, \varepsilon_{t}\right)-c\left(I_{t}, K_{t}\right)-r B_{t}+N_{t}\right)=0
$$

where $\mu_{2} \geq 0$ and by the firm's cash-flow constraint $\pi\left(K_{t}, \varepsilon_{t}\right)-c\left(I_{t}, K_{t}\right)-r B_{t}+$ $N_{t} \geq 0$.

Given the assumptions on the shapes of the firm's short-run profit function and adjustment cost function, conditions (A.2)-(A.5) are both necessary and sufficient for an optimum and therefore completely characterize the solution of the optimization problem (A.1).

Equation (3.3) in text follows immediately from equations (A.2) and (A.5) and equation (3.3) follows from equations (A.3) and (A.4), upon noting that by equation (A.2) $\mu_{2}=-1+q_{t} / c_{I}\left(I_{t}, K_{t}\right)$

In order to characterize further the relation between the multipliers $\mu_{1}$ and $\mu_{2}$ we note that if both the financial constraints are binding, loosening the constraint on new debt issue entails two marginal effects, an increase in new debt issue and an increase in investment that is allowed by the additional marginal cash-flow made available by new debt issue. Loosening the cash-flow constraint instead, entails at the margin only an increase in investment, therefore the difference $\mu_{1}-\mu_{2}$ between the new debt issue multiplier and the cash-flow multiplier must reflect only the effect of the increase in new debt issue.

Lemma A.1: The difference between the multiplier of the constraint on new debt issue $\mu_{1}=\partial H\left(q_{t}\right) / \partial \bar{N}$ and the multiplier of the cash-flow constraint $\mu_{2}=$ $\partial H\left(q_{t}\right) / \partial \varphi$, where $\varphi=0$ is the level of the cash-flow constraint is $\partial H\left(q_{t}\right) / \partial \bar{N}-$ $\partial H\left(q_{t}\right) / \partial \varphi=1+q_{t}^{B} \geq 1-q_{t} / c_{I}\left(I_{t}, K_{t}\right)$ where $I_{t}$ is the level of investment that solves the firm's optimization problem (A.1) at time $t$.

Proof: Consider first that when the financial constraints are not binding $\mu_{1}=$ $\mu_{2}=0$, the result follows since in this case $1+q_{t}^{B}=0$. If the financial constraints are binding instead $N_{t}=\bar{N}$ and $\pi\left(K_{t}, \varepsilon_{t}\right)-c\left(\bar{I}, K_{t}\right)-r B_{t}+\bar{N}=0$, where $\bar{I}$ is the upper bound on investment that is achieved by the firm due to the binding financial constraints. That both investment and new debt issue are at an upper bound in this case, follows since the adjustment cost function is an increasing function of investment. Differentiating the cash-flow constraint with respect to investment $\bar{I}$ and new debt issue $\bar{N}$ it is straightforward to show that $\partial \bar{I} / \partial \bar{N}=1 / c_{I}\left(\bar{I}, K_{t}\right) \geq 0$. Differentiating the value function with respect to new debt issue $\bar{N}$ it is then easy to show that:

$$
\frac{\partial H\left(q_{t}\right)}{\partial \bar{N}}=q_{t}^{B}+\frac{q_{t}}{c_{I}\left(\bar{I}, K_{t}\right)}
$$

Now rewrite the cash-flow constraint as $-\pi\left(K_{t}, \varepsilon_{t}\right)+c\left(\bar{I}, K_{t}\right)+r B_{t}-\bar{N}=\varphi$ for 
$\varphi=0$, such that an increase in $\varphi$ entails a relaxation of the constraint. Note then that differentiation of the constraint with respect to investment $\bar{I}$ and the cash-flow constraint level $\varphi$ shows that $\partial \bar{I} / \partial \varphi=1 / c_{I}\left(\bar{I}, K_{t}\right) \geq 0$. Differentiating the value function with respect to cash-flow $\varphi$ it is then easy to show that:

$$
\frac{\partial H\left(q_{t}\right)}{\partial \varphi}=-1+\frac{q_{t}}{c_{I}\left(\bar{I}, K_{t}\right)}
$$

The result then follows combining equations (A.6) and (A.7) with the first order conditions of the optimization problem.

The results established in Lemma 4.1 and in equations (A.2) to (A.7) allow for a complete characterization of the second stage of the firm's optimization problem. We can therefore turn to the analysis of the first stage and of the properties of the firm's investment function and of the firm's value function summarized in Propositions 4.1 and Propositions 4.2.

Proof of Proposition 4.1: The proof of this proposition is already largely developed in section 4, we provide here however some additional results that allow to clarify the main argument and to describe more precisely the properties of the investment function. Consider first the shape of the investment function defined in equation (4.1), and recall that it is obtained by equating the shadow price of capital to the marginal cost of firm's investment. This in turn implies that the equality $q_{t}=c_{I}\left(I\left(q_{t}\right), K_{t}\right)$ holds as an identity in the relevant range of the shadow price of capital $q_{t}$. Differentiating this identity with respect to the shadow price of physical capital $q_{t}$ we can show that $I_{q}\left(q_{t}\right)=1 / c_{I I}\left(I\left(q_{t}\right), K_{t}\right)$. We can further differentiate this equality with respect to $q_{t}$ to show that $I_{q q}\left(q_{t}\right)=-c_{I I I}\left(I\left(q_{t}\right), K_{t}\right) / c_{I I}\left(I\left(q_{t}\right), K_{t}\right)^{3}$. We note that since the adjustment cost function is increasing and convex $I_{q}\left(q_{t}\right) \geq 0$ so that the function $I\left(q_{t}\right)$ defined in equation (4.1) is increasing in the shadow price of physical capital $q_{t}$. The curvature of the investment function instead is shown to depend on the third derivative of the adjustment cost function, such that for $c_{I I I}\left(I\left(q_{t}\right), K_{t}\right) \geq 0$ the investment function is concave in $q_{t}$ or $I_{q q}\left(q_{t}\right) \leq 0$ and conversely for $c_{I I I}\left(I\left(q_{t}\right), K_{t}\right) \leq 0$ the investment function is convex in $q_{t}$ or $I_{q q}\left(q_{t}\right) \geq 0$, formally:

$$
\operatorname{sign}\left(I_{q q}\left(q_{t}\right)\right)=-\operatorname{sign}\left(c_{I I I}\left(I\left(q_{t}\right), K_{t}\right)\right.
$$

The first part of the proposition states that there exist in each time period a value $\widetilde{q}$ such that for $q_{t}<\widetilde{q}$ at the first stage the firm decides not to invest so that $I\left(q_{t}\right)=0$ identically, while for $q_{t} \geq \widetilde{q}$ the firm invests such that $I\left(q_{t}\right) \geq 0$ and the investment function takes the form of equation (4.1) as long as the financial constraints are not binding. The existence of such a value for the shadow price of physical capital depends on the properties of the value function $H\left(q_{t}\right)$ defined in equation (4.2). Since this function is increasing and continuous and given its limiting behavior as $q_{t}$ converges to 0 from above, we just need to assume that there exist two values of the shadow price of capital $q^{\prime}<q^{\prime \prime}$ such that $H\left(q^{\prime}\right)<0$ and $H\left(q^{\prime \prime}\right)>0$. Since $H\left(q_{t}\right)$ is a continuous function it follows then by the intermediate value theorem that there exists a value $\widetilde{q}$ such that $q^{\prime}<\widetilde{q}<q^{\prime \prime}$ and $H(\widetilde{q})=0$. We note that the definition of the value function given in equation (4.2) implies that this value $\widetilde{q}$ of the shadow price of capital is a fixed point of the function 
defined by the average physical capital adjustment cost $c\left(I\left(q_{t}\right), K_{t}\right) / I\left(q_{t}\right)$. Since in the equilibrium defined by the second stage of the firm's optimization problem, if the financial constraints are not binding the shadow price of capital is equal to the marginal cost of investment and therefore the equality $q_{t}=c_{I}\left(I\left(q_{t}\right), K_{t}\right)$ holds as an identity, for $q_{t}<\widetilde{q}$ the marginal cost of investment is lower than or equal to the average cost of investment or $c_{I}\left(I\left(q_{t}\right), K_{t}\right)<c\left(I\left(q_{t}\right), K_{t}\right) / I\left(q_{t}\right)$ and for $q_{t} \geq \widetilde{q}$ the marginal cost of investment is greater than or equal to the average cost of investment or $c_{I}\left(I\left(q_{t}\right), K_{t}\right) \geq c\left(I\left(q_{t}\right), K_{t}\right) / I\left(q_{t}\right)$.

Proof of Proposition 4.2: Follows from the results of Proposition 4.1. 


\section{References}

Abel A. B. (1983) 'Optimal Investment under Uncertainty', American Economic Review, Vol. 73, No. 1, March, pp. 228-233.

http://ideas.repec.org/a/aea/aecrev/v73y1983i1p228-33.html

Abel A. B. (1985) 'A Stochastic Model of Investment, Marginal q and the Market Value of the Firm', International Economic Review, Vol. 26, No. 2, June, pp. 305-322.

http://ideas.repec.org/p/nbr/nberwo/1484.html

Abel A. B. and Eberly J. C. (1994) 'A Unified Model of Investment Under Uncertainty', American Economic Review Vol. 84, No. 5, December, pp. 1369-1384.

http://ideas.repec.org/a/aea/aecrev/v84y1994i5p1369-84.html

Abel A. B. and Eberly J. C. (1996) 'Optimal Investment with Costly Reversibility', Review of Economic Studies, Vol. 63, No. 4, October, pp. 581-593.

http://ideas.repec.org/p/nbr/nberwo/5091.html

Abel A. B. and Eberly J. C. (1999) 'The Effects of Irreversibility and Uncertainty on Capital Accumulation', Journal of Monetary Economics, Vol. 44, No. 3, December, pp. 339-377. http://ideas.repec.org/p/nbr/nberwo/5363.html

Abel A. B., Dixit A. K., Eberly J. C. and Pindyck R. S. (1996) 'Options, the Value of Capital, and Investment', The Quarterly Journal of Economics, Vol. 111, No. 3, August, pp. 753-777. http://ideas.repec.org/p/nbr/nberwo/5227.html

Bernanke B., Gertler M. and Gilchrist S. (1996) 'The Financial Accelerator and the Flight to Quality', The Review of Economics and Statistics, Vol. 78, No. 1, February, pp. 1-15. http://ideas.repec.org/a/tpr/restat/o78y1996i1p1-15.html

Bertola G. and Caballero R. J. (1990) 'Kinked Adjustment Costs and Aggregate Dynamics', in Blanchard J. O. and Fischer S. (eds.) 'NBER Macroeconomics Annual 1990', Cambridge, The MIT Press, pp. 237-288.

http://ideas.repec.org/p/fth/coluec/465.html

Bertola G. and Caballero R. J. (1994) 'Irreversibility and Aggregate Investment', Review of Economic Studies, Vol. 61, No. 2, April, pp. 223-246.

http://ideas.repec.org/a/bla/restud/v61y1994i2p223-46.html

Billingsley (1968) Convergence of Probability Measures, New York, John Wiley \& Sons. http://eu.wiley.com/WileyCDA/WileyTitle/productCd0471197459, descCd-description.html

Bond S. and Meghir C. (1994) 'Dynamic Investment Models and the Firm's Financial Policy', Review of Economic Studies, Vol. 61, No. 2, April, pp. 197-222.

http://ideas.repec.org/p/cpr/ceprfm/0013.html

Caballero R. J. (1990) 'Expenditure on Durable Goods: a Case for Slow Adjustment', The Quarterly Journal of Economics, Vol. 105, No. 3, August, pp. 727-743.

http://ideas.repec.org/p/fth/coluec/444.html 
Caballero R. J. (1993) 'Durable Goods: an Explanation for their Slow Adjustment', Journal of Political Economy, Vol. 101, No. 2, pp. 351-384.

http://ideas.repec.org/a/ucp/jpolec/v101y1993i2p351-84.html

Caballero R. J. (1994) 'Notes on the Theory and Evidence on Aggregate Purchases of Durable Goods', Oxford Review of Economic Policy, Vol. 10, No. 2, Summer, pp. 107-117. http://ideas.repec.org/a/oup/oxford/v10y1994i2p107-17.html

Caballero R. J. and Engel E. M. R. A. (1999) 'Explaining Investment Dynamics in U.S. Manufacturing: a Generalized (S,s) Approach', Econometrica, Vol. 67, No. 4, July, pp. 783-826. http://ideas.repec.org/a/ecm/emetrp/v67y1999i4p783-826.html

Caballero R. J., Engel E. M. R. A. and Haltiwanger J. C. (1995) 'Plant-Level Adjustment and Aggregate Investment Dynamics', Brookings Papers on Economic Activity, Vol. 1995, No. 2, pp. 1-54.

Carlsson M. and Laséen S. (2005) 'Capital Adjustment Patterns in Swedish Manufacturing Firms: What Model do They Suggest?', The Economic Journal, Vol. 115, No. 506, October, pp. 969-986. http://ideas.repec.org/p/hhs/uunewp/2001_015.html

Chirinko R. S. (1993) 'Econometric Models and Empirical Findings for Busi-ness Investment', Financial Markets, Institutions and Instruments, Vol. 2, No. 4, pp. 1-78.

Cooper R., Haltiwanger J. and Power L (1999) 'Machine Replacement and the Business Cycle: Lumps and Bumps', American Economic Review, Vol. 89, No. 4, September, 921946. http://ideas.repec.org/a/aea/aecrev/v89y1999i4p921-946.html

Deaton A. (1991) 'Saving and Liquidity Constraints', Econometrica, Vol. 59, No. 5, September, pp. 1121-1248. http://ideas.repec.org/a/ecm/emetrp/v59y1991i5p1221-48.html

Deaton A. (1992) Understanding Consumption, Oxford, Clarendon Press, Clarendon Lectures in Economics. books.google.de

Dixit A. K. And Pindyck R. S. (1994) Investment Under Uncertainty, Princeton, New Jersey, Princeton University Press. http://press.princeton.edu/titles/5474.html

Doms M. and Dunne T. (1998) 'Capital Adjustment Patterns in Manufacturing Plants', Review of Economic Dynamics, Vol. 1, No. 2, April, pp. 409-429. http://ideas.repec.org/a/red/issued/v1y1998i2p409-429.html

Fazzari S. M., Hubbard R. G. and Petersen B. C. (1988) 'Financing Constraints and Corporate Investment', Brookings Papers on Economic Activity, 1, pp. 141-206.

http://ideas.repec.org/p/nbr/nberwo/2387.html

Gilchrist S. and Himmelberg C. P. (1995) 'Evidence on the role of cash flow for investment', Journal of Monetary Economics, Vol. 36, pp. 541-572.

http://ideas.repec.org/a/eee/moneco/v36y1995i3p541-572.html 
Gomes J. (2001) 'Financing Investment', American Economic Review, Vol. 91, No. 5, December, pp. 1263-1285. http://ideas.repec.org/a/aea/aecrev/v91y2001i5p1263-1285.html

Greenwald B., Stiglitz J. E. and Weiss A. (1984) 'Informational Imperfections in the Capital Market and Macroeconomic Fluctuations', American Economic Review, Papers and Proceedings, Vol. 74, No. 2, May, pp. 194-199.

http://ideas.repec.org/a/aea/aecrev/v74y1984i2p194-99.html

Hayashi F. (1982) 'Tobin's Marginal and Average q: a Neoclassical Inter-pretation', Econometrica, Vol. 50, pp. 213-224.

http://ideas.repec.org/a/ecm/emetrp/v50y1982i1p213-24.html

Hayashi F. (1985) 'The Effect of Liquidity Constraints on Consumption: a CrossSectional Analysis', The Quarterly Journal of Economics, Vol. 100, No. 1, February, pp. 183-206. http://ideas.repec.org/a/tpr/qjecon/v100y1985i1p183-206.html

Hoshi T., Kashyap A. and Scharfstein D. (1991) 'Corporate Structure, Liquidity and Investment: Evidence from Japanese Industrial Groups', The Quarterly Journal of Economics, February, pp. 33-60. http://ideas.repec.org/a/tpr/qjecon/v106y1991i1p33-60.html

Hubbard G., Kashyap A. K. And Whited T. M. (1995) 'Internal Finance and Firm Investment', Journal of Money, Credit and Banking, Vol. 27, No. 3, August, pp. 683-701. http://ideas.repec.org/p/nbr/nberwo/4392.html

Jensen M. C. and Meckling W. H. (1976) 'Theory of the Firm: Managerial Behavior, Agency costs and Ownership Structure', Journal of Financial Economics, Vol. 3, No. 4, October, pp. 305-360. http://ideas.repec.org/a/eee/jfinec/v3y1976i4p305-360.html

Kaplan S. N. and Zingales L. (1997) 'Do Investment-Cash Flow Sensitivities Provide Useful Measures of Financing Constraints?', The Quarterly Journal of Economics, Vol. 112, No. 1, February, pp. 169-215.

http://ideas.repec.org/a/tpr/qjecon/v112y1997i1p169-215.html

Karatzas I. and Shreve S. E. (1988) Brownian Motion and Stochastic Calculus, New York, Springer. books.google.de

Kiyotaki N. and Moore J. (1997) 'Credit Cycles', Journal of Political Economy, Vol. 105, No. 2, pp. 211-248. http://ideas.repec.org/a/ucp/jpolec/o105y1997i2p211-48.html

Krylov N. V. (1980) Controlled Diffusion Processes, New York, Heidelberg, Berlin, Springer-Verlag.

Malliaris A. G. and Brock W. A. (1982) Stochastic Methods in Economics and Finance, Amsterdam, North Holland.

http://www.elsevier.com/wos/find/bookdescription.cws_home/500550/description\#description

Merton R. C. (1990) Continuous Time Finance, Cambridge MA and Oxford UK, Blackwell. books.google.de 
Modigliani F. and Miller M. H. (1958) 'The Cost of Capital, Corporation Finance and the Theory of Investment', American Economic Review, Vol. 48, No. 3, June, pp. 261-297. http://findarticles.com/p/articles/mi_hb5037/is_199012/ai_n18314025

Modigliani F. and Miller M. H. (1963) 'Corporate Income Taxes and the Cost of Capital: A Correction', American Economic Review, Vol. 53, No. 3, June, pp. 433-443.

Myers S. C. and Majluf N. S. (1984) 'Corporate Financing and Investment Decisions when Firms Have Information the Investors Do Not Have', Journal of Financial Economics, Vol. 13, No.2,. June, pp. 187-221.

http://ideas.repec.org/p/nbr/nberwo/1396.html

Nilsen Ø. A. and Schiantarelli F. (2003) 'Zeros and Lumps in Investment: Empirical Evidence on Irreversibilities and Nonconvexities', The Review of Economics and Statistics, Vol. 85, No. 4, November, pp. 1021-1037.

http://ideas.repec.org/a/tpr/restat/v85y2003i4p1021-1037.html

Runkle D. E. (1991) 'Liquidity Constraints and the Permanent-Income Hypothesis: Evidence from Panel Data', Journal of Monetary Economics, Vol. 27, pp. 73-98. http://ideas.repec.org/a/eee/moneco/v27y1991i1p73-98.html

Stiglitz J. E. and Weiss A. (1981) 'Credit Rationing in Markets with Imperfect Information', American Economic Review, Vol. 71, No. 3, June, pp. 393-410.

http://ideas.repec.org/a/aea/aecrev/v71y1981i3p393-410.html

Stiglitz J. E. and Weiss A. (1983) 'Incentive Effects of Terminations: Applications to the Credit and Labor Markets', American Economic Review, Vol. 73, No. 5, December, pp. 912-927. http://ideas.repec.org/a/aea/aecrev/v73y1983i5p912-27.html

Whited T. M. (1992) 'Debt, Liquidity Constraints, and Corporate Investment: Evidence from Panel Data', The Journal of Finance, Vol. 47, No. 4, September.

http://ideas.repec.org/a/bla/jfinan/v47y1992i4p1425-60.html

Zeldes S. P. (1989) 'Consumption and Liquidity Constraints: an Empirical Investigation', Journal of Political Economy, Vol. 97, No. 2, April, 305-346.

http://ideas.repec.org/a/ucp/jpolec/v97y1989i2p305-46.html 
Please note:

You are most sincerely encouraged to participate in the open assessment of this article. You can do so by either rating the article on a scale from 5 (excellent) to 1 (bad) or by posting your comments.

Please go to:

www.economics-ejournal.org/economics/journalarticles/2008-9

The Editor 